\title{
BLOG: FERRAMENTA ESTRATÉGICA DE COMUNICAÇÃO ORGANIZACIONAL
}

\author{
BLOG: STRATEGIC TOOL FOR \\ ORGANIZATIONAL COMMUNICATION
}

\author{
Recebido 22/02/2012 \\ Aceito 26/07/2012 \\ Mônica Mota Tassigny ${ }^{1}$ \\ Marcus Vinicius de Oliveira Brasil ${ }^{2}$ \\ Maria Clara Bugarim ${ }^{3}$ \\ Fábio Luiz Benício Maia Nogueira ${ }^{4}$
}

\section{RESUMO}

Este trabalho tem como objetivo geral debater a importância do blog como ferramenta da comunicação organizacional interna e externa, destacando-o como uma nova modalidade de comunicação que pode colaborar no gerenciamento de informações e na construção de uma imagem empresarial competitiva, motivando o público interno e fidelizando clientes. É um estudo de caso, de natureza qualitativa, a partir de pesquisa bibliográfica, documental e de campo. A investigação documental foi feita em um site relacionado à ferramenta GoogleDocs. Na pesquisa de campo, optou-se pela análise de conteúdo. Como resultado, observa-se que as empresas estão implantando processos de comunicação organizacionais mais participativos e estratégicos. Nessa perspectiva, concluiu-se que os blogs organizacionais constituem instrumentos com poder de comunicação bidirecional instantâneo, aptos a assegurarem uma interação de informações entre a organização e seus públicos, constituindo-se uma estratégia no fortalecimento da imagem frente ao público alvo, funcionando como ferramenta colaborativa de gestão da informação.

Palavras-chave: Blog; Comunicação; Tecnologia da Informação; Internet; Organizações

\footnotetext{
${ }^{1}$ Universidade de Fortaleza-UNIFOR, Programa de Pós-Graduação em Administração-PPGA. E-mail: mônica.tass@gmail.com

${ }^{2}$ Universidade Federal do Ceará-UFC- Campus Cariri/ Bolsista da FUNCAP. Doutorando do Programa de Pós-Graduação em Administração-PPGA da UNIFOR. E-mail: mvobrasil@ufc.br

${ }^{3}$ Doutoranda do Programa de Engenharia e Gestão do Conhecimento da Universidade Federal de Santa Catarina-UFSC. E-mail: mclarabugarim@unifor.br

${ }^{4}$ Mestre em Administração Universidade de Fortaleza-UNIFOR. E-mail: bemanog@hotmail.com
} 


\section{ABSTRACT}

This study aimed to discuss the general importance of the blogs as a tool for internal and external organizational communication, highlighting as a new mode of communication that can help the information management and build a competitive corporate image, motivating the workforce customer loyalty. It is a case study, qualitative in nature, a literature review, a documentary and a field research. The documentary research was done in a site related to GoogleDocs tool. In the field research was used content analysis. As a result, it is observed that companies are implementing organizational communication processes more participative and strategic. From this perspective, it was concluded that blogs are tools with organizational power of instant two-way communication, able to ensure an interaction of information between the organization and its stakeholders, being a strategy to strengthen the image of the organization to the clients, functioning as a collaborative tool of information management.

Keywords: Blog; Communication; Information; Technology; Internet; Organizations

\section{INTRODUÇÃO}

Novas práticas administrativas e gerenciais têm surgido nas últimas décadas não só como resultado da busca incessante pela produtividade, qualidade e satisfação do cliente, mas também em consequência da preocupação com o meio ambiente. Tanto a busca pela excelência empresarial quanto a preocupação com o consumidor e com o futuro do planeta têm produzido novas concepções de gestão de negócios. São mudanças econômicas com transformações para os mercados, para a sociedade como um todo e para os relacionamentos entre seres humanos dentro e fora da empresa. Nesse cenário, destaca-se o importante papel da comunicação organizacional na comunicação e na gestão da informação no ambiente organizacional e nas novas formas de relação da empresa com o público externo.

A Comunicação Organizacional constitui, assim, elemento estratégico para gestão e administração das empresas (CARDOSO, 2007), pois representa um importante canal de troca de informações e de relacionamento entre o ambiente interno das empresas e o mundo exterior a elas. É somente por meio do desenvolvimento de boas estratégias de comunicação organizacional que se torna possível avaliar o posicionamento mercadológico da empresa, construir a cultura organizacional e constituir uma identidade corporativa.

Este artigo, resultado de pesquisa bibliográfica, documental e de campo, objetiva debater a importância do blog organizacional como ferramenta estratégica da comunicação organizacional (interna e externa) no gerenciamento da informação, destacando-o como uma modalidade de comunicação que pode colaborar na construção de uma imagem empresarial competitiva, motivando o público interno e fidelizando clientes, possibilitando, assim, melhor negociação com os fornecedores e com o público externo.

As fontes bibliográficas caracterizam um estudo teórico de natureza hermenêutica, portanto, interpretativo, a partir de autores como: Albertin e Albertin (2005); Rezende e Abreu (2008); Alonso (2007); Orduña (2007); Baldissera (2001); Gaspar (2005); Lévy(1996); Castels (1997) etc. Para o embasamento da comunicação organizacional como um elemento estratégico, são citados teóricos como: Colnago (2006); Maximiano (2007); Cruz (2005); Cardoso (1991, 2007); Putnan (1982, 2004); Silva (2007) etc. Optou-se pelo embasamento da comunicação organizacional como um elemento estratégico na realização dos objetivos e da intencionalidade das organizações.

Os teóricos supracitados fundamentaram o pressuposto da dimensão estratégica que a comunicação vem assumindo nas organizações, no mundo contemporâneo. As comunicações 
organizacional e empresarial são tratadas, neste artigo, como categorias similares e não mais se restringem à simples produção de instrumentos, mas também se referem à posição social e ao funcionamento da organização como um todo: desde seu clima interno, sua cultura, até suas relações institucionais. (CARDOSO, 2007). A comunicação e a organização são partes ligadas de forma inseparável, isomórficas (PUTNAN, 1982).

A pesquisa documental analisou e comparou os resultados do blog http:// sobregoogledocs com os resultados de uma pesquisa de campo entre profissionais liberais (administradores, jornalistas, advogados e psicólogos, etc) como amostra intencional para estudo de caso sobre a importância das ferramentas de comunicação e gerenciamento de informações. $\mathrm{Na}$ pesquisa de campo, aplicou-se um questionário com questões abertas para profissionais liberais escolhidos como amostra intencional, representando um caso fundamental em função de suas práticas e de sua relevância na representação do fenômeno investigado (FLICK, 2009).

Como resultado geral, destacou-se que muitos dos problemas que uma grande empresa costuma enfrentar são consequências da falta de comunicação, seja esta interna ou externa. As estratégias para superação de problemas existem a partir do conhecimento destes, por meio da comunicação organizacional clara e transparente no acesso às informações.

Outra constatação foi a de que um dos objetivos das estratégias de comunicação deve ser a construção de uma imagem competitiva (COLNAGO, 2006; TORQUATO, 1991), motivando o público interno, fidelizando clientes, possibilitando melhor negociação com os fornecedores e com o público externo, entre outros. Se a comunicação inexiste, a imagem da empresa fica a mercê da percepção do público, sem que se possa fazer determinada intervenção.

Por fim ressalta-se que, entre os novos recursos tecnológicos disponíveis, atualmente, o blog é uma opção eficiente e segura para a comunicação organizacional (GONÇALVES; TERRA, 2007), já que, dentre suas qualidades, destaca-se a sua rapidez, que pode garantir a chegada da informação ao seu público interno e externo, permitindo, inclusive, um retorno sobre o funcionamento da empresa, com base na possibilidade dada ao público de comentar e enviar sugestões sobre as informações disponibilizadas.

\section{A IMPORTÂNCIA ESTRATÉGICA DA COMUNICAÇÃO ORGANIZACIONAL}

O fluxo de informações que percorrem a comunicação organizacional pode ser realizado por intermédio de vários canais, deixando, muitas vezes, na responsabilidade das assessorias de comunicação a escolha da ferramenta indicada para a organização. Vale ressaltar que algumas assessorias são facilmente induzidas a acreditarem que estão cumprindo seu papel, atuando na harmonização do ambiente de trabalho apenas editando pequenos boletins e jornais internos, enquanto a comunicação organizacional não se restringe apenas a essa função.

Os jornais internos, boletins e mesmo revistas constituem expressivas e importantes parcelas da comunicação interna e representam uma fatia significativa do processo de comunicação, no entanto, há outras formas, meios, projetos e recursos que devem ser experimentados (CRUZ, 2005).

A comunicação organizacional (CARDOSO, 2007) é muito mais do que o conjunto de técnicas e meios de comunicação, pois estes podem ser estrategicamente pensados para a adequada projeção da identidade de uma organização ao ambiente no qual pretende construir uma imagem favorável, uma vez que são determinantes para a formação e para a manutenção estratégica da imagem institucional das empresas (COLNAGO, 2006; SILVA, 2007). Esse processo 
dá-se com a definição do objetivo em primeiro lugar, seguida da estratégia da mídia para a perfeita comunicação dos objetivos, acrescida das estratégias de conteúdo e mensagem, a fim de realizar análises dos resultados obtidos e corrigir eventuais desvios, estabelecendo uma troca contínua entre organização e público (interno e externo).

A comunicação organizacional constitui, assim, o processo decisivo para integração da empresa com todos os seus públicos de interesse. Ainda contribui para o aperfeiçoamento de seus processos, para a organização como um todo e para sua sobrevivência no mercado, pois possibilita melhor fluxo na informação. Nestes termos, pode-se afirmar que fundamenta estratégia privilegiada na integração da empresa com todos os seus públicos de interesse.

A informação e os processos de comunicação sempre estiveram presentes na evolução das estratégias empresariais e na própria evolução das organizações. Por isso, hoje, muito mais do que em épocas passadas, torna-se necessário entender a complexidade que envolve a informação e os processos comunicacionais na gestão estratégica das organizações. Afinal, vivemos numa era de ritmo acelerado de transformações e contextos cada vez mais complexos, onde as organizações precisam buscar novas lógicas de gestão para enfrentar a competitividade (CARDOSO, 2007, p.1126).

Conforme Cardoso (2007), a informação e a comunicação são elementos fundamentais na prática de gestão empresarial no mundo globalizado. Na contemporaneidade, abrem-se variadas perspectivas de estudos da comunicação empresarial, enfocando-se práticas comunicacionais que têm contribuído significativamente para o desenvolvimento de estratégias de negócios.

Tais estudos desvelam novas dimensões e possibilidades da comunicação organizacional como ferramentas das estratégias de gestão empresarial. Tanto as mudanças tecnológicas como alterações em certos paradigmas para a análise da comunicação organizacional inauguraram mudanças culturais, sobretudo, pela nova realidade virtual em rede (LÉVY, 1996; CASTELS, 1997). Essa realidade é capaz de aproximar as empresas, as pessoas e as informações no mundo todo.

Nessa direção, a comunicação organizacional passa a constituir elemento estratégico de gestão, sendo indicador fundamental da cultura organizacional, não se restringindo à simples produção de instrumentos de comunicação. De acordo com Albertin e Albertin (2005, p.3), "Os modelos, cultura, políticas, estruturas, processos organizacionais, incluindo suas evoluções, devem ser considerados na utilização de TI, seja porque são afetados, seja porque afetam o uso".

A dimensão estratégica que a comunicação vem assumindo nas organizações, em parte, é porque integra a cultura organizacional e vem modificando paulatinamente antigos limites e culturas. Não mais se restringe à simples produção de instrumentos, mas também se refere à posição social e ao funcionamento da organização desde seu clima interno até suas relações institucionais. A comunicação e a organização são partes ligadas de forma inseparável, constituem o mesmo fenômeno, portanto, são isomórficas (CARDOSO, 1991; PUTNAN et al, 2004).

Segundo Silva (2007), no mundo contemporâneo, a comunicação organizacional desempenha, numa empresa, cinco funções-chave: reforço de espírito de equipe; liderança, motivação e influência; esclarecimento de dúvidas; resolução de problemas e tomada de decisões; e gestão de conflitos e negociação.

Nesses termos, a comunicação organizacional é o elemento chave para constituir um mecanismo de instalação de imagens subjetivas no imaginário coletivo sobre a empresa, pois, "[...] ainda que haja porta-vozes autorizados, todos os membros são portadores do discurso da organização, mesmo aqueles que não falam ou contradizem o discurso oficial" (COLNAGO, 2006, s/p).

O discurso escapa, em boa medida, da vontade da organização, já que o intercâmbio de informações que se processa nas empresas é um grande fator que desencadeia as impressões 
que se formam a respeito da organização e, como tal, contribui para a imagem da instituição.

Já a comunicação interna deve estar voltada para definições de como engajar funcionários e torná-los porta-vozes eficientes da organização, tanto como fazê-los compreender qual o objetivo da organização e de como fazê-los aceitar as regras e mudanças.

É primordial desenvolver uma política que consiga fazer com que todos compartilhem um sentimento de pertencimento, identificando-se com a cultura existente e aceitando suas predeterminações, além disso, é importante lembrar sempre que quanto mais as empresas esforçam-se para refletir uma imagem melhor ao meio externo, maiores e mais duras são as cobranças internas, o que acaba por gerar tensões e desvios entre a comunicação interna e externa (COLNAGO, 2006, s/p).

Por fim, a comunicação organizacional externa tem um poder influenciador e disseminador e, assim como a interna, colabora para a criação de uma imagem favorável no mercado. Para isso, é imprescindível que seja pautada por informações sérias e verdadeiras, que dizem respeito aos reais atributos da identidade corporativa, elemento fundamental para a criação de uma imagem sólida e crível (SILVA, 2007; MAXIMIANO, 2007). Esse conjunto de mensagens transmite a identidade, que é recebida pelos públicos em forma de imagens e se torna o elemento de intermediação entre cultura, identidade e imagem (BALDISSERA, 2001).

\section{O FENÔMENO BLOG}

Nos últimos anos, assistiu-se ao fenômeno da evolução tecnológica de comunicação, característica herdada da globalização. O acompanhamento desse avanço tecnológico tornouse algo indispensável às organizações, que, nos últimos anos, tiveram que reciclar as suas ferramentas de comunicação interna, junto aos seus colaboradores, e externa, junto aos clientes, substituindo ou, pelo menos, adequando os meios de comunicação tradicionais, como as circulares normativas, as revistas e os boletins, por instrumentos atuais, como o e-mail, e as redes sociais, por exemplo: “[...] é quase impensável conceber uma organização, em que os seus computadores não estejam interligados em uma rede informática comum, através da qual se possa aceder à Internet, Intranet, Extranet, e-mail, aplicações de mensagens instantâneas, aplicações colaborativas entre ouras possíveis (SILVA, 2007, s/p)".

Mais recentemente, uma nova ferramenta veio agregar as diversas possibilidades de armazenamento e distribuição de mensagens entre os colaboradores e os clientes das organizações: os blogs ou weblogs. Os primeiros blogs, de acordo com Julio Alonso (2007, p.16), “[...] surgiram no início da década e foram criados por usuários particulares que queriam publicar diários on-line e se viam frustrados diante da dificuldade e do esforço do processo existente até então".

Inicialmente, eram páginas pessoais que abordavam inúmeros temas relacionados a um indivíduo ou a um grupo ao qual pertencia. Com acesso e publicação facilitados, os blogs ganharam espaço entre os internautas, principalmente, pelo seu formato bem pessoal, que possibilita ao indivíduo compor, na maioria das vezes, uma página com as suas características, por meio da publicação, por exemplo, de fotos e opiniões individuais, além de reservar um espaço para comentários de leitores.

Pressupondo a ideia de que um usuário comum pode ser um produtor de informações, os blogs fortaleceram-se com a possibilidade de interação entre o receptor e o emissor, deixando de ser apenas uma página pessoal, para evoluir e se transformar em um canal de comunicação importante, a partir do qual é possível navegar para obter informações sobre temas, trabalho, 
viagens, novidades, obras literárias, humor, protestos, dentre outros, com a facilidade de encontrar uma linguagem mais informal, de fácil acesso, e dinâmica.

Os blogs tornaram-se filtros do mundo internáutico, a partir dos quais se pode ter acesso às inúmeras informações, utilizando recursos de textos, imagens, áudios, vídeos, gráficos e outros artifícios que conquistam e dão prazer aos internautas. "A Internet e seus recursos vêm ocasionando o aparecimento de organizações baseadas na informação e no conhecimento. Tais organizações aproveitam tecnologias para compartilhar o conhecimento entre todos os que participam do processo de dinamizar o negócio, ou seja, o capital humano ou (intelectual) da empresa" (REZENDE; ABREU, 2008, p. 194).

A evolução dos blogs fez com que essa ferramenta de comunicação se transformasse em um grande difusor de informações, gerando não só o interesse dos navegadores, mas também o de empresas, fato que levou o blog para o mundo dos negócios. Na contemporaneidade, exercem uma grande função dentro da comunicação organizacional, intermediando o contato entre a empresa, os clientes e colaboradores.

\section{O BLOG COMO FERRAMENTA DE COMUNICAÇÃO IN- TERNA E EXTERNA}

Através de uma comunicação claramente orientada pelas diretrizes estratégicas da organização, é possível destacar as faces da identidade que mais interessam, determinando quais conteúdos devem ser divulgados e quais os meios mais eficientes para que essa mensagem intencionalmente orientada possa chegar ao público-alvo.

Com esse pensamento e aproveitando o crescimento exponencial dos blogs como meio de comunicação, inúmeras empresas passaram a utilizá-los como mecanismo de comunicação organizacional, tendo em vista as potencialidades que esse recurso oferece tanto no nível interno quanto no nível externo.

A partir da utilização da internet, criou-se uma nova forma de ação e interação, possibilitando aos indivíduos e às organizações interagirem numa escala sem precedentes. Nesse contexto, "inscrevemos novas formas de comunicar e criamos espaços onde podemos organizar novos tipos de relação com pessoas que, em outras circunstâncias, provavelmente não chegaríamos a conhecer" (GASPAR, 2005).

Essencialmente, os blogs organizacionais são utilizados para disponibilizar informações, a fim de alcançarem seus objetivos, podendo ser de caráter interno ou externo. Colnago (2006) aponta várias razões para sua criação por uma organização: tornar a empresa perita na sua área de negócio; relacionar-se com clientes e com os meios de comunicação social; promover colaboração ou cooperação interna, gestão do conhecimento, recrutamento; testar ideias ou produtos; e posicionar a empresa no topo de busca da Internet. Tal ferramenta constitui-se como uma grande evolução da comunicação organizacional. "Os blogs organizacionais não são um meio de ruptura com a estratégia de comunicação organizacional existente nas organizações, mas sim uma possibilidade de melhorar essa estratégia através do preenchimento das lacunas dos tradicionais meios de comunicação organizacional e dos meios digitais atualmente existentes nas organizações" (GASPAR, 2005, s/p).

Externamente, os blogs organizacionais têm como objetivo criar o vínculo entre a empresa, os clientes e o mercado, baseando-se na descrição das principais atividades exercidas pela empresa e valorizando o consumidor através do interesse na marca ou em um produto específico. Uma vez que "[...] através de uma comunicação claramente orientada pelas diretrizes 
da organização, é possível destacar as faces da identidade que mais interessam" (COLNAGO, 2006, s/p).

Os blogs externos podem ser encontrados com função de vendas, de relacionamento, de caráter institucional e de marketing da empresa, adequando-os aos segmentos de público existente. Os blogs relacionados a vendas são direcionados àquele público que busca comprar produtos específicos ou conhecer os produtos e serviços oferecidos, diferente dos blogs destinados a relacionamento, que têm com objetivo estabelecer e fortalecer o vínculo entre os consumidores e a organização, tendo com público-alvo os consumidores por meio, por exemplo, de serviços de suporte técnico e serviços de atendimento ao consumidor. De acordo com Vasconcellos (2005, p. 27): "Assim, a estrutura organizacional da empresa é estabelecida de modo a manter esse foco no cliente".

O blog organizacional tem como finalidade a valorização da marca e o estabelecimento da identidade da organização no mercado, dedicando-se, principalmente, aos executivos, presidentes de empresas etc. Segundo Laudon e Laudon (2007, p. 59, grifo do autor), “Os usuários finais são representantes de departamentos externos ao grupo de sistemas de informação para quem os aplicativos são desenvolvidos. E eles estão cada vez mais assumindo um papel cada vez maior no projeto e no desenvolvimento de sistemas de informação".

Já os blogs relacionados ao marketing, disponibilizam os serviços da assessoria de comunicação da empresa. O Relações-Públicas, a Assessoria de Imprensa e a equipe de Publicidade e Propaganda podem articular e comunicar a visão estratégica da companhia e oferecer para interessados (clientes, diretores, funcionários, fornecedores, mídia, autoridades, sindicatos, etc.) uma face da empresa mais clara e periódica; responder e antecipar qualquer necessidade de informação da imprensa, órgãos públicos ou reguladores; promover e proteger a reputação da companhia; e articular e comunicar a visão estratégica da empresa.

Em complemento aos blogs externos, os internos dedicam-se aos colaboradores das organizações, tornando-se ferramenta de compartilhamento de informações e conhecimentos, fomentando a troca de ideias entre as equipes e reforçando a cultura organizacional. Para Gonçalves e Terra (2007), os blogs internos servem como elo principal entre todos os departamentos e podem atuar fortemente como gestores das mudanças internas da companhia. "A grande vantagem é o fato de eles serem muito mais fáceis de instalar, manejar, modificar e manter atualizados, além de ser um melhor suporte para conversações e oferecer mais facilidades para a busca de informação" (ALONSO, 2007, p.20).

Isso permite às empresas estarem sempre prontas a fornecerem respostas às demandas externas e internas de uma forma consciente, voluntária e sistemática, e mais humanizada em seus próprios meios de comunicação, o que a torna um diferencial.

\footnotetext{
Enquanto que o 'Fale Conosco' da empresas não são humanizados, ou seja, sabemos que uma mensagem está sendo enviada sem saber se teremos uma resposta da solicitação, reclamação, opinião ou elogio. Com os blogs, a interação é bem mais próxima da realidade da empresa. A dinâmica que envolve as respostas simples e ágeis pode se tornar um diferencial para as organizações que incorporem a ferramenta ao seu rol de comunicação institucional, o que, a nosso ver, só traz e garante uma boa imagem da empresa. Ou, pelos menos, uma percepção de empresa transparente, disposta a dialogar com seus públicos (GONÇALVES; TERRA, 2007, s/p).
}

Outro ponto muito importante é o desenho do blog, ou seja, se o site é bem desenhado, torna-se um atrativo natural aos internautas, principalmente, se as informações são disponibilizadas de maneira clara, de fácil acesso, acabando por se constituir numa vantagem competitiva (HAYLOCK; MUSCARELLA, 1999). 
As principais características do objeto estudado, a ferramenta Googledocs, são as seguintes: é uma interface de acesso a documentos (textos e planilhas) com formato Microsoft Office; permite a criação, a edição e o compartilhamento de documentos disponibilizados pelos usuários a partir da web, o acesso através da conta do Gmail ou Blogger; e, ainda, é totalmente online, sem necessidade de instalação de softwares; e permite publicar na web automaticamente.

\section{METODOLOGIA E RESULTADOS}

Esta pesquisa foi do tipo exploratória, tendo como o método a interpretação hermenêutica. O objetivo geral desta pesquisa foi debater a importância do blog como ferramenta da comunicação organizacional interna e externa, destacando-o como nova modalidade de comunicação, que pode colaborar na construção de uma imagem empresarial competitiva, motivando o público interno, fidelizando clientes e possibilitando, assim, melhor negociação com os fornecedores e com o público externo. Foram realizadas pesquisas bibliográficas e documentais, e utilizadas técnicas de análise de conteúdo, a partir de estudo de caso. "O círculo hermenêutico cumpre-se, desconstruindo um a um os diferentes objetos teóricos que a ciência constrói sobre si própria e com eles, as diferentes imagens que dá de si, a fim de tornar compreensível por que razão foram construídos esses objetos e não outros, essas imagens e não outras" (SANTOS, 1989, p.13).

[...] a reflexão sobre a ciência que se faz não pode escapar ao círculo hermenêutico, o que significa, antes de mais, não podermos compreender qualquer das suas partes (as diferentes disciplinas científicas) sem termos alguma compreensão de como 'trabalha' o seu todo, e, vice-versa, não podermos compreender a totalidade sem termos alguma compreensão de como "trabalham" as suas partes [...] (GADAMER apud SANTOS, 1989, p.11).

A pesquisa documental analisou e comparou os resultados do blog http:// sobregoogledocs com os resultados de uma pesquisa de campo realizada com profissionais liberais (administradores, jornalistas, advogados e psicólogos, etc.) como amostra intencional para estudo de caso sobre a importância das ferramentas de comunicação e gerenciamento de informações. Na pesquisa de campo, aplicou-se um questionário com indagações abertas para sujeitos escolhidos como amostra intencional, representando um caso fundamental em função de suas práticas e de sua relevância na representação do fenômeno investigado (FLICK, 2009).

A pesquisa exploratória foi feita utilizando levantamentos em fontes secundárias. $O$ presente estudo fundamenta-se em uma vasta revisão bibliográfica sobre o assunto. Fazendo-se uso de revistas, de livros e de pesquisas realizadas relacionadas ao tema. As técnicas de coleta de dados foram relacionadas com a parte prática da investigação em uma pesquisa científica, sendo um conjunto de processos que servem a determinado fim (LAKATOS; MARCONI, 1991, p. 222,223).

Para um conhecimento mais individualizado e qualitativo, é aconselhável se usar a técnica de estudos de casos. É necessário utilizar a técnica de estudos de casos para alcançar um conhecimento mais apurado sobre o objeto da pesquisa (BOGDAN; BIKLEN, 1994, p.47). Conforme Holanda (2003, p.9), "Os estudos de casos podem ser descritivos, exploratórios [...] ou, ainda, avaliativos [...]. Em síntese, um descreve, outro teoriza e o terceiro testa a teoria".

Utilizou-se, assim, do método de estudo de caso, partindo-se do princípio de que o caso pode ser considerado representativo de todos os outros ou mesmo de casos semelhantes. Este consiste no estudo de determinados indivíduos, profissões, condições, instituições, grupos ou comunidades, com a finalidade de obter conhecimento exploratório. "A investigação deve 
examinar o tema escolhido, observando todos os fatores que o influenciaram e analisando-o em todos os seus aspectos" (LAKATOS; MARCONI, 1991, p. 108).

Fez-se, por fim, uma análise interpretativa do conteúdo das questões abertas, criando ou inferindo categorias que não podiam ser reduzidas ao método estatístico (BRUYNE; HERMAN; SCHOUTHEETE, 1977, BARDIN, 1977). Para análise dos resultados, foram feitas interpretações da fala dos respondentes. Os resultados foram obtidos através de uma pesquisa de campo intencional feita por questionário contendo 4 perguntas e enviado a profissionais liberais (administradores, jornalistas e psicólogos, etc.). Logo após, foi feita a análise de conteúdo dos mesmos e a discussão dos resultados.

A pesquisa documental constou da retirada da opinião de alguns dos respondentes dos blogs pesquisados, bem como, na pesquisa de campo, foram trazidas somente as respostas de alguns questionários selecionados por critério meramente qualitativo. As perguntas feitas no questionário aplicado nesta pesquisa foram: 1- Como você utiliza o Googledocs?; 2- Quais são as principais vantagens e desvantagens do blog?; 3- O material que utiliza ou visita mais?; 4- Em que o blog pode ajudar na pesquisa científica?. Desta feita, as impressões foram sintetizadas de acordo com dois blocos de respondentes, distinguindo as respostas da pesquisa documental e as da virtual, sendo que, no quadro 1 , estão os comentários dos não usuários ou usuários iniciantes e, no quadro 2, os usuários mais experientes do Googledocs.

As análises dos resultados entre a pesquisa documental e a de campo (quadro 1 ) revelaram que existem profissionais nas organizações que nunca acessaram a ferramenta estudada, o Googledocs. Isso pode ser percebido nos comentários de A, B, 1 e 2, no entanto, o respondente $B$ constata uma necessidade de ordem comunicacional "[...] vê vantagens em mais de uma pessoa editar um documento, e se comunicarem via chat".

Esse argumento é reforçado pela resposta do usuário E que "[...] salienta a praticidade da ferramenta, dispensando mídias de gravação." No entanto, esse reforço parece ser contrariado pelas respostas dos profissionais 3 e 5 . Albertin (2000, p. 99) ressalta que: "As empresas não obtêm suas vantagens em virtude apenas da utilização de TI. Muitas vezes, a vantagem é atingida a partir do estabelecimento de uma efetiva parceria, uma vez que a entrega efetiva de produtos e serviços de sistemas de informações requer uma parceria efetiva entre os principais atores envolvidos com os sistemas".

Já os profissionais C, D acham prática a sua utilização, enquanto o respondente 3 discorda: "Eu não utilizo o Googledocs. Não acho pratico a sua utilização, pois gosto de arquivar as alterações/revisões por data, e lá não é possível". Tecnicamente, percebe-se uma possível necessidade de melhorias na ferramenta.

As empresas precisam adequar seu ambiente organizacional e comunicacional ao advento dos blogs, pois, na era da Internet, leia-se também na Sociedade do Conhecimento, a informação deve estar disponibilizada de forma a tornar seu acesso rápido e deve estar mais bem distribuída entre as partes envolvidas. Segundo Vassos (1997, p. 219), "A chave do sucesso das estratégias de abertura na Internet é um fluxo contínuo de informação baseada na necessidade do cliente". O Googledocs parece sinalizar nessa direção, principalmente após o advento da web de segunda geração, denominada Web 2. É um serviço gratuito e de acesso livre, em que não só as pessoas, mas também as empresas podem disponibilizar documentos, planilhas e apresentações com formato idêntico ao Microsoft Office, sem a necessidade de implementar uma estrutura de intranet (rede interna). Como esses documentos estão disponibilizados no Google, contam com a segurança da informação do maior provedor de serviços de internet da atualidade (serviços: Tradutor, Livros, Acadêmico, Blogs, You Tube, Agenda, Fotos, Reader, Sites, Grupos, Google Reader, Google Pack etc). 


\begin{tabular}{|c|c|}
\hline \multicolumn{2}{|c|}{ NÃO USUÁRIOS OU USUÁRIOS INICIANTES DO GOOGLEDOCS } \\
\hline PESQUISA DOCUMENTAL & PESQUISA DE CAMPO \\
\hline $\begin{array}{l}\text { A. "[...] comenta que não conhece, mas não tem tem- } \\
\text { po de explorar, fará isso em outro momento". }\end{array}$ & 1. "Eu não uso o Googledocs..." \\
\hline $\begin{array}{l}\text { B. "[...] não conhecia, mas vê vantagens em mais de } \\
\text { uma pessoa editar um documento, e se comunicarem } \\
\text { via chat". }\end{array}$ & $\begin{array}{l}\text { 2. "Sobre a pesquisa abaixo, não tenho muito a contribuir. } \\
\text { Motivo: ainda não faço uso dessa ferramenta". }\end{array}$ \\
\hline $\begin{array}{l}\text { C. "[...] comenta que nosso trabalho está claro, dando } \\
\text { as informações necessárias para quem quiser utilizar } \\
\text { a ferramenta". }\end{array}$ & $\begin{array}{l}\text { 3. "Eu não utilizo o Googledocs. Não acho prático a sua } \\
\text { utilização, pois gosto de arquivar as alterações/revisões } \\
\text { por data, e lá não é possível". }\end{array}$ \\
\hline $\begin{array}{l}\text { D. "[...] salienta a praticidade da ferramenta, dispen- } \\
\text { sando mídias de gravação". }\end{array}$ & $\begin{array}{l}\text { 4. "Só utilizei o Googledocs uma vez, para compartilhar } \\
\text { arquivo em ppt, em que eu e um colega do doutorado es- } \\
\text { távamos trabalhando para apresentarmos um seminário. } \\
\text { Ressalto que essa utilização ocorreu em momentos não } \\
\text { concomitantes". }\end{array}$ \\
\hline $\begin{array}{l}\text { E. "[...] entende o Google docs como um escritório } \\
\text { virtual". }\end{array}$ & $\begin{array}{l}\text { 5. "Eu não gosto de blogs porque são muito pessoais, aí } \\
\text { varia muito da opinião de cada um sobre certo assunto. } \\
\text { Para mim, a vantagem que existe em um blog é quando } \\
\text { você compartilha da mesma opinião e ideia, e os comen- } \\
\text { tários são favoráveis ao complemento da ideia". }\end{array}$ \\
\hline
\end{tabular}

Quadro 1: Comparação entre respostas da Pesquisa Documental e de Campo de não usuários ou usuários iniciantes do Googledocs

Fonte: Adaptado pelos pesquisadores (2011).

Nesta parte da pesquisa, passou-se a análise dos resultados entre os profissionais liberais que efetivamente utilizam o Googledocs (quadro 2), sendo importante salientar como essas pessoas utilizam a ferramenta nas organizações. Para tal, foram analisados dados da pesquisa documental e de campo. Todavia, como afirma Davenport (1998, p.150) "[...] infelizmente, a maior parte dos profissionais de informação não sabe o que torna a informação significativa, e muito menos de que maneiras se podem agregar valor a ela". Em outras palavras, trata-se de Conhecimento que dota a informação de significado, sendo este o primeiro passo para a agregação de valor. E somente o trabalhador do conhecimento pode executar isso de forma eficaz.

É observado, no quadro 2, que todos os respondentes, sem exceção, asseveram o uso da ferramenta Googledocs como benéfico, explicando, de uma forma geral, o seu uso, como por exemplo, o caso do profissional 9: "Utilizo na empresa em que trabalho (Jornal) para compartilhar documentos, planilhas de projetos e agenda pessoal. Compartilhamento em tempo real. A edição do material por terceiros. A possibilidade de acessar esses documentos de qualquer lugar do mundo que tenha conexão com internet/ mobilidade. A economia de papel. Utilizo o google agenda/ doc - planilhas."

\begin{tabular}{|l|l|}
\hline \multicolumn{2}{|c|}{ USUÁRIOS EXPERIENTES DO GOOGLEDOCS } \\
\hline \multicolumn{1}{|c|}{ PESQUISA DOCUMENTAL } & \multicolumn{1}{c|}{ PESQUISA DE CAMPO } \\
\hline $\begin{array}{l}\text { F.“[... Google docs é uma ferramenta que integra dois } \\
\text { serviços em uma única interface permitindo trocar im- } \\
\text { pressões e opiniões enriquecendo o trabalho." }\end{array}$ & $\begin{array}{l}\text { 6."O meu maior intuito é de que essas pessoas possam } \\
\text { editar ou apenas ler os meus trabalhos, sendo este um } \\
\text { aplicativo interessante e facilitador de compartilhamen- } \\
\text { tos. [...] Desvantagens- O risco de apagar os artigos de } \\
\text { maneira muito simples, sendo bastante complicado a re- } \\
\text { cuperação destes”. }\end{array}$ \\
\hline
\end{tabular}




\begin{tabular}{|c|c|}
\hline \multicolumn{2}{|c|}{ USUÁRIOS EXPERIENTES DO GOOGLEDOCS } \\
\hline PESQUISA DOCUMENTAL & PESQUISA DE CAMPO \\
\hline $\begin{array}{l}\text { G. "Percebi que a grande maioria das colegas des- } \\
\text { conhecia o Google Docs e sua funcionalidade, mas } \\
\text { ficaram encantadas com a ferramenta e as diversas } \\
\text { possibilidades, como: poder criar, editar e salvar um } \\
\text { documento online, sem a necessidade de instalar um } \\
\text { software. Além de poder compartilhar a edição com } \\
\text { outras pessoas, tornando-se um ambiente colaborati- } \\
\text { vo de aprendizagem." }\end{array}$ & $\begin{array}{l}\text { 7.“[...] Vantagem: Estar disponível na internet para } \\
\text { que a pessoa em qualquer lugar possa acessar. } \\
\text { Desvantagens: Alguns comandos e mensagens em inglês. } \\
\text { Adaptar-se aos comandos um pouco diferenciados do Mi- } \\
\text { crosoft Office". }\end{array}$ \\
\hline $\begin{array}{l}\text { H. "O Google Docs é uma ferramenta permite uma } \\
\text { maior praticidade e rapidez no acesso de documentos } \\
\text { on line. Percebo que o tutorial da ferramenta de uso } \\
\text { do espaço virtual para a publicação, edição, atualiza- } \\
\text { ção e compartilhamento de documentos está base- } \\
\text { ado nas orientações originais do site e é bem claro. } \\
\text { O alerta de acessibilidade do software a todos que } \\
\text { possuírem login e senha, e a necessidade de cuidados } \\
\text { adicionais, como o uso de senhas mais complexas é su- } \\
\text { gerida para evitar correr o risco de informações serem } \\
\text { modificadas." }\end{array}$ & $\begin{array}{l}\text { 8. "Utilizo para compartilhar arquivos e documentos junto } \\
\text { a colegas de trabalho e alunos. É uma ótima ferramenta } \\
\text { de construção em conjunto. Vantagens: rapidez, dinamis- } \\
\text { mo, fácil acesso (popularidade), divulgação, atualização, } \\
\text { fácil inclusão de vídeos, textos e fotos. Desvantagens: rí- } \\
\text { gido controle de acesso e informalidade da informação" }\end{array}$ \\
\hline $\begin{array}{l}\text { I. "Ele possibilita que se comece um trabalho em um } \\
\text { determinado local e continue escrevendo em outro, } \\
\text { basta estar conectado. É como se estivesse escreven- } \\
\text { do em um editor de texto igual ao Word, com recursos } \\
\text { semelhantes para formatação do texto, como também } \\
\text { criar planilhas no editor de planilha [...]." }\end{array}$ & $\begin{array}{l}\text { 9. "Utilizo na empresa em que trabalho (Jornal) para } \\
\text { compartilhar documentos, planilhas de projetos e minha } \\
\text { agenda. Compartilhamento em tempo real. A edição do } \\
\text { material por terceiros. A possibilidade de acessar esses } \\
\text { documentos de qualquer lugar do mundo que tenha co- } \\
\text { nexão com internet/ mobilidade. A economia de papel. } \\
\text { Utilizo o google agenda/ doc - planilhas." }\end{array}$ \\
\hline
\end{tabular}

Quadro 2: Comparação entre respostas da Pesquisa Documental e de Campo de usuários experientes.

Fonte: Adaptado pelos pesquisadores (2011).

Também foi percebida uma preocupação e um elogio da segurança da informação pelo

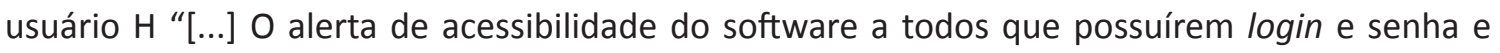
a necessidade de cuidados adicionais, como o uso de senhas mais complexas, é sugerida para evitar correr o risco de informações serem modificadas"; mas que foi criticada pelo usuário 8, tendo isso como uma desvantagem: "rígido controle de acesso e informalidade da informação".

De acordo com Tanenbaum (1994, p.659), "os problemas de segurança das redes podem ser divididos nas seguintes áreas interligadas: sigilo, autenticação, não repudiação e controle de integridade". Na questão do sigilo, o importante é impossibilitar pessoas não autorizadas de terem acesso a informações secretas. Na autenticação, deve-se verificar quem está fazendo a transação, sabendo se é a pessoa mesmo que afirma ser. A não repudiação, além de verificar as assinaturas digitais, prova o teor de um pedido, bem como o horário da solicitação. No controle de integridade, o usuário pode verificar se a mensagem é mesmo legítima, e não algo manipulado.

As informações adequadas, confiáveis, oportunas e de bom conteúdo são essenciais nas tomadas das decisões para o planejamento estratégico e para a monitoração. Os processos decisórios, na verdade, devem estar associados fortemente à questão da informação. Faz-se necessária a criação de um espírito crítico filtrador das informações realmente necessárias, baseadas em uma ética que contemple a privacidade e a segurança das informações.

No entendimento de Allison (1996, p.72, tradução nossa), existem três preocupações básicas com a questão dos níveis de segurança na Internet: segurança das informações, segurança das transações, segurança das pessoas: "teoricamente, qualquer mecanismo de segurança criado pelo homem pode ser quebrado, dando tempo suficiente e havendo dedicação para tal". 
A questão da ética, da privacidade e da segurança na rede mundial de computadores é um tema que tem sido amplamente debatido, no entanto, muitos cientistas da computação têm avançado em suas pesquisas, objetivando criar mecanismos de segurança cada vez mais eficientes.

Ainda, os usuários 6 e 7 parecem apontar desvantagens do Googledocs com relação ao quesito da interface. 0 profissional 6 adverte sobre "o risco de apagar os artigos de maneira muito simples, sendo bastante complicado a recuperação destes". Já o respondente 7 sinaliza para as desvantagens de "alguns comandos e mensagens em inglês. Adaptar-se aos comandos um pouco diferenciados do Microsoft Office". Ou seja, tecnicamente não considera a interface tão amigável.

A informática e a tecnologia da informação surgiram bem a tempo de fomentar essas experiências, trazendo para dentro das empresas o mundo exterior. É possível, a qualquer momento, todos os componentes da organização terem acesso, ao mesmo tempo, aos dados da empresa, tornando as organizações mais horizontalizadas. Para isso, podem-se utilizar as tecnologias da Internet e aplicá-las no sistema de informação interno de cada empresa, criando, dessa forma, uma espécie de plataforma comum. Eis algumas vantagens: maior eficiência na instalação e manutenção do sistema; facilidade de utilização (reduzindo custos de formação); integração mais fácil de diversas plataformas e sistemas operativos. "As organizações têm como desafio determinar o grau de transformação que aceitarão, o que poderá levar às mudanças de modelos de negócio e a maiores questionamentos de sua contribuição para o seu desempenho" (ALBERTIN; ALBERTIN, 2005, p.13).

\section{CONSIDERAÇÕES FINAIS}

A comunicação organizacional é um conjunto de ações interventoras por parte de uma empresa para construir sua identidade corporativa, transformar esta em mensagens de comunicação que transmitam a própria imagem da empresa e disseminá-la entre o público estrategicamente selecionado.

As últimas e céleres mudanças econômicas e tecnológicas colocam novos desafios para a competitividade das empresas. Surgem inúmeros e novos meios de comunicação a partir da utilização da internet. Essa última abre perspectivas favoráveis à criação de novas formas comunicação, para as organizações interagirem com seus públicos, quebrando barreiras de espaço e de acesso às informações e modificando as relações sociais como um todo.

Nesse particular, os blogs organizacionais para comunicação empresarial (interna ou externa) constituem uma nova ferramenta estratégica, pela possibilidade rápida de projeção positiva da imagem da empresa, pois têm o poder de comunicação bidirecional instantânea a partir da interação de informações entre a organização e seus públicos.

No Brasil, esse recurso comunicativo que chegou com as empresas multinacionais vem despertando o interesse da grande maioria das organizações, mas ainda existem empresas que os veem com preconceito, pois são vistos como diários virtuais de "adolescentes" ou "internautas" que os utilizam para lazer.

Os Blogs Organizacionais, no mundo contemporâneo, representam um canal de informação da empresa, que pode ser facilmente atualizado, além de ser uma fonte confiável de informações (e conhecimentos) que podem auxiliar clientes e fornecedores e, ainda, permitir processos colaborativos e de interação. Nessa direção, tornam-se um diferencial competitivo para as empresas, num mercado em que a concorrência investe em tecnologia e pesquisa (Business Intelligence) para buscar inovação e sucesso. 
É preciso, porém, tomar cuidado com o que será escrito, já que informação tem um valor representativo, e o blog, por ser um espaço aberto, pode ser alvo dos concorrentes. Contudo, tal ferramenta tem demonstrado ser uma forma colaborativa e de trocas culturais entre público e organizações, favorável àquelas empresas que saíram na frente e implantaram este instrumento de comunicação.

As informações adequadas, confiáveis, oportunas e de bom conteúdo são essenciais nas tomadas das decisões para o planejamento estratégico e para a monitoração dos resultados. Os processos decisórios, na verdade, devem estar associados fortemente à questão do acesso e da disponibilização da informação como estratégia de comunicação interna e externa. Acredita-se, portanto, que a utilização dos Blogs pode favorecer a criação de um espírito crítico filtrador das informações realmente necessárias, capazes de fundamentar uma ética que contemple, a um só tempo, a privacidade e a segurança das informações.

Nesses termos, pode-se ainda inferir que a utilização do blog como ferramenta de comunicação organizacional constitui estratégia importante para demonstrar transparência e aceitar o diálogo com o consumidor. Concluiu-se, portanto, que os blogs organizacionais constituem instrumentos com poder de comunicação bidirecional instantâneo, aptos a assegurarem uma interação de informações entre a organização e seus públicos. Portanto, pode ser estratégia nos fortalecimentos da imagem e do público alvo, funcionando como ferramenta colaborativa (interna e externa) de gestão da informação. 


\section{REFERÊNCIAS}

ALBERTIN, A. L. Comércio Eletrônico: modelo, aspectos e contribuições de sua aplicação. 2a ed. São Paulo: Atlas, 2000.

ALBERTIN, A. L.; ALBERTIN, R. M. de M. Tecnologia de informação e desempenho empresarial: as dimensões de seu uso e sua relação com os benefícios de negócio. São Paulo: Alas, 2005. 202p.

ALLISON, Wayne. Internet Business Primer. Illinois: Sourcebooks Inc., 1996.

ALONSO, J. Blogs e empresas. In: ORDUÑA, O. Blogs: Revolucionando os meios de comunicação. São Paulo: Thomson, 2007, p.17-30.

BALDISSERA, R. Estratégia, Comunicação e Relações Públicas. Campo Grande: Intercom, 2001.

BARDIN, L. Análise de conteúdo. Lisboa: Edições 70, 1977.

BOGDAN, R. C.; BIKLEN, S. K. Investigação qualitativa em educação: uma introdução à teoria e aos métodos. Porto: Porto Editora, 1994 (Colecção Ciências da Educação).

BRUYNE, P. de; HERMAN, J.; SCHOUTHEETE, M. de. Dinâmica da pesquisa em ciências sociais: os pólos da prática metodológica. Traduzido por Ruth Joffily. Rio de Janeiro: F. Alves, 1977.

CARDOSO, O. O. Os paradigmas no ensino da comunicação - a transgressão epistemológica. Comunicação \& Sociedade, ano 10 , n. 17, p. 9-32, ago. 1991.

CARDOSO, O. O. Comunicação Organizacional versus comunicação empresarial: novos desafios teóricos. Rio de Janeiro: RAP, 2007, p.1123-44. In http:// www.scielo.br/scielo.php?pid=S003476122006000600010 \& script $=\mathrm{sci}$ abstract\&tlng=pt Acesso em 20/02/2011.
COLNAGO, C. K. A Comunicação organizacional como fator determinante para a construção da imagem institucional. Disponível em: http:// www.dominiopublico.gov.br 2006. Acesso em: 11 set. 2010

CRUZ, V. M. B. da. O papel da Comunicação Organizacional. FACCAT. Rio de Janeiro, 2005.

DAVENPORT, Thomas $\mathrm{H}$. Ecologia da informação: por que só a tecnologia não basta para o sucesso na era da informação. Traduzido por Bernadette Siqueira Abrão. São Paulo: Futura, 1998.

GASPAR, A. O blog e a sua dimensão organizacional: Análise de um objeto impírico. Disponível em: <http://bocc.ubi.pt/pag/ gaspar-ana-blog-dimensao-organizacional. pdf> 2005. Acesso em: 17 mar. 2010.

GONÇALVES, M.; TERRA, C. Blogs corporativos: nova ferramenta de comunicação empresarial e/ou realidade ainda pouco brasileira. Disponível em: http://www.rp-bahia.com.br/ revista/blogs_corporativos 2007. Acesso em: 18/02/2011.

FLICK, U. Desenho da Pesquisa Qualitativa. Coleção Pesquisa Qualitativa. Trad. Roberto Cataldo Costa. Porto Alegre: Artmed, 2009.

HAYLOCK, C.F; MUSCARELA, L. Net success: 24 leaders in web commerce show you how to put the internet to work for your business. United States of America: Library of Congress Cataloging-in-Publication Data, 1999.

LAKATOS, E. M.; MARCONI, M. Fundamentos de metodologia científica. 3 ed. São Paulo: Atlas, 1991.

LAUDON, Jane P.; LAUDON, Keneth C. Sistemas de informação gerenciais. 7ạ Ed. São Paulo: Pearson/Prentice Hall.458p. 2007.

LÉVY, P. As tecnologias da inteligência: o futuro do pensamento na era da informática. Rio de Janeiro: Editora 34, 1996. 
MAXIMIANO, A. C. A. Teoria Geral da Administração. São Paulo: Atlas, 2007.

PUTNAN, L. L. Paradigms for organizational communication research: an overview and synthesis. The Western Journal of Speech Communication, v. 46, n. 2, p. 192-206, 1982.

PUTNAN, L.L.; PHILLIPS, N.; CHAPMAN, P. Metáforas da comunicação e da organização. In: CLEGG, S. R.; HARDY, C.; NORD, W. R. (Orgs.). Handbook de estudos organizacionais: ação e análises organizacionais. São Paulo: Atlas, 2004. v. 3, p. 77-125.

REZENDE, D.A.; ABREU, A. F. Tecnologia da Informação: aplicada a sistemas de informação empresariais. 5 ed. São Paulo: Alas, 2008.

SANTOS, Boaventura de Sousa. Introdução a uma ciência pós-moderna. Rio de Janeiro: Graal, 1989.

SILVA, H.N.da. 0 papel dos blogs na comunicação organizacional. Disponível em: http://blog.lisbonlab.com/estudos/o-papeldos-blogs-na-comunicacao-organizacional/> 2007. Acesso em: 17 mar. 2010.

TANENBAUM, Andrew S. Redes de Computadores. 3 ed. Rio de Janeiro: Campus, 1994.

TORQUATO, G. Cultura, Poder Comunicação e Imagem. São Paulo: Pioneira, 1991.

VASCONCELLOS, E. et. al. (Org). Competitividade e negócios eletrônicos: experiências de empresas brasileiras. São Paulo: Atlas, 2005. 159 p.

VASSOS, Tom. Marketing Estratégico na Internet: estratégias comprovadas para você ter sucesso com o marketing de seus produtos e serviços. Traduzido por Arão Sapiro. São Paulo: Makron Books, 1997. 